\title{
AVALIAÇÃO DE ACESSIBILIDADE - ESTUDO DE CASO EM QUADRAS DO BAIRRO VILA UNIÃO
}

\author{
LIMA, Manuela de Castro Mendonça (1); \\ COSTA, José Rógeres Magalhães (2); \\ (1) Instituto Federal do Ceará, Especialista em Gerenciamento de Obras \\ e-mail:manuela.lima@ifce.edu.br \\ (2) Tribunal de Justiça do Ceará, Especialista em Direito Constitucional \\ e-mail:rogerescosta@hotmail.com
}

\begin{abstract}
RESUMO
A falta de conhecimento ou entendimento das leis e normas relativas à acessibilidade, além de erros de leitura e execução de projetos são os principais problemas encontrados para quem está disposto a ver as cidades e suas edificações (públicas ou privadas) adequadas e acessíveis a todos. A transformação gera custos financeiros e impactos físicos e até psicológicos. A cidade é reconhecida pelos seus usuários e suas mudanças necessitam ser bem planejadas e executadas, de maneira que não ocorram transtornos e retrabalho na construção.
\end{abstract}

Palavras chave: acessibilidade; projeto; cidade.

\begin{abstract}
The lack of knowledge or understanding of the laws and regulations about accessibility, as well as errors in reading and execution of projects are the main problems encountered for those who are willing to see the cities and their buildings (public or private) suitable and accessible to all. The transformation generates financial costs and physical and even psychological impacts. The city is recognizes by its users and its changes need to be well planned and executed, so that there is no disruption and rework in the construction.
\end{abstract}

Keywords: accessibility; project; city.

\section{INTRODUÇÃO}

Considerando o regime democrático do Brasil, a Constituição vigente garante a todos os cidadãos brasileiros o direito a igualdade, a saúde, a educação, a moradia, o trabalho, 0 lazer, dentre outros. Estes cidadãos são pessoas de diferentes condições sociais, crenças religiosas, etnias e outros aspectos como: faixa etária (crianças, adultos, idosos), gênero, pessoas com deficiência permanente ou temporária, pessoas com mobilidade reduzida e etc.

Falando em deficiência, de acordo com a Organização Mundial da Saúde (OMS), o termo ainda está em um processo de desenvolvimento, pois, os modelos existentes são diversos e dependentes de fatores culturais, variando de país para país. Enquanto na convenção dos Organismos das Nações Unidas (ONU), são definidas regras padrão sobre lgualdade de 


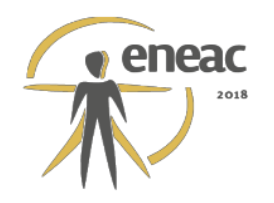

Oportunidades para Pessoas com Deficiência, guiando os países sobre a promoção da equalização. Em dezembro de 2006, uma nova convenção da ONU teve como objetivo "promover, proteger e garantir o desfrute pleno e igual de todos os direitos humanos e liberdades fundamentais por todas as pessoas com deficiência, e promover o respeito a sua dignidade inerente" (Artigo 1).

Porém, encarando a realidade de muitos lugares, devido à falta de espaços adequados e acessíveis, algumas pessoas com deficiência física deixam de realizar atividades simples. Estas pessoas deixam de vivenciar a cidade em sua plenitude e se limitam aos lugares que apresentam condições mínimas de acessibilidade; pois, quando não inclusivo, um espaço pode gerar uma segregação silenciosa (DUARTE e COHEN, 2007).

Assim, o termo Acessibilidade entra no contexto para se caracterizar como um direito fundamental que engloba a mobilidade, a participação e a integração das atividades cotidianas (ZURBA, 2016). E é nesta vertente, vislumbrando espaços acessíveis, que algumas cidades, em todo o mundo, estão modificando seu desenho e incentivando sua população a ter mudanças atitudinais. Mudanças estas que devem envolver a todos, independentes de classe social, cultura ou credo.

No caso de Fortaleza, tivemos como exemplo uma obra de requalificação urbana, que foi realizada no ano de 2017, no bairro Vila União. As ruas adjacentes ao Hospital Infantil Albert Sabin passaram por modificações, incluindo as caixas de rolamento e calçadas. Estas alterações tiveram o intuito à promoção e a priorização dos pedestres que frequentam aquela região e que, na sua maioria, estão acompanhados por crianças com algum caso de debilitação da sua saúde ou em fase de recuperação. Além disso, na mesma região periférica ao hospital, funcionam outros órgãos de saúde, como por exemplo, a Associação Peter Pan que é um centro de apoio à criança diagnosticada com câncer.

Além desta intervenção realizada no ano passado (2017), a região possui um diferencial: a Rua da Esperança (Rua Alberto Montezuma). Este projeto, inaugurado em 2016, teve as participações das iniciativas públicas e privadas, os quais projetaram e executaram uma via que favorecesse os pedestres e fosse um espaço lúdico para as crianças. Ressalta-se que tal projeto só se tornou viável devido ao Programa Adoção de Praças e Áreas Verdes da Cidade de Fortaleza lançado em abril de 2013 e oficializado pelo decreto 13.142 da Prefeitura Municipal de Fortaleza (PMF).

Assim, acreditando que uma obra positiva pode ser uma boa influencia para outros projetos, e que ruas vivas e repletas de frequentadores se tornam lugares ideais para uma convivência agradável (CHOAY, 1979); a Prefeitura de Fortaleza realizou estas novas intervenções nas demais ruas próximas a Rua da Esperança.

Porém, será que estas modificações estão saindo como o esperado? Este trabalho apresentará alguns pontos diagnosticados na região e a sua real eficiência.

\section{METODOLOGIA}

Este trabalho de avaliação é composto por um diagnóstico do local, realizado pelos os autores. Além de registros fotográficos da situação atual e de imagens das vias antes das obras.

Os pontos analisados serão ressaltados e relacionados às normas técnicas da ABNT (NBR 9050-2015) e ao Decreto ํ55.296, de 2 de dezembro de 2004.

E por fim, uma avaliação será feita para uma melhor reflexão da problemática e das possíveis atitudes que tanto a iniciativa pública como a privada deveriam ter para suas próximas intervenções. 


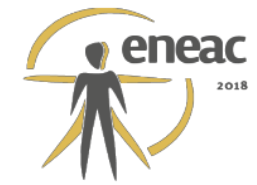

\section{RESULTADOS}

\subsection{Apresentação da região}

A região que sofreu a intervenção encontra-se no bairro Vila União, Regional IV de Fortaleza, e está delimitada pelas ruas João Araripe (à oeste), Jorge Acúrcio (à leste), Aberlado Marinho (à sul) e Francisco Lorda (à norte). Esta última via, a mais movimentada atualmente, está funcionando como desvio das obras do VLT (Estação Borges de Melo), além de fazer uma ligação direta da Avenida Luciano Carneiro à Rua Engenheiro Edmundo Almeida Filho. Também, é por esta mesma rua que se acessa a Rua da Esperança e é onde está localizado o ponto de ônibus mais utilizado pelos frequentadores temporários ou não do Hospital Albert Sabin. Só neste ponto, circulam 15 linhas de ônibus oficializadas pela Etufor (Empresa de Transporte Urbano de Fortaleza), sendo duas linhas do tipo corujão.

Figura 1 - Apresentação da área

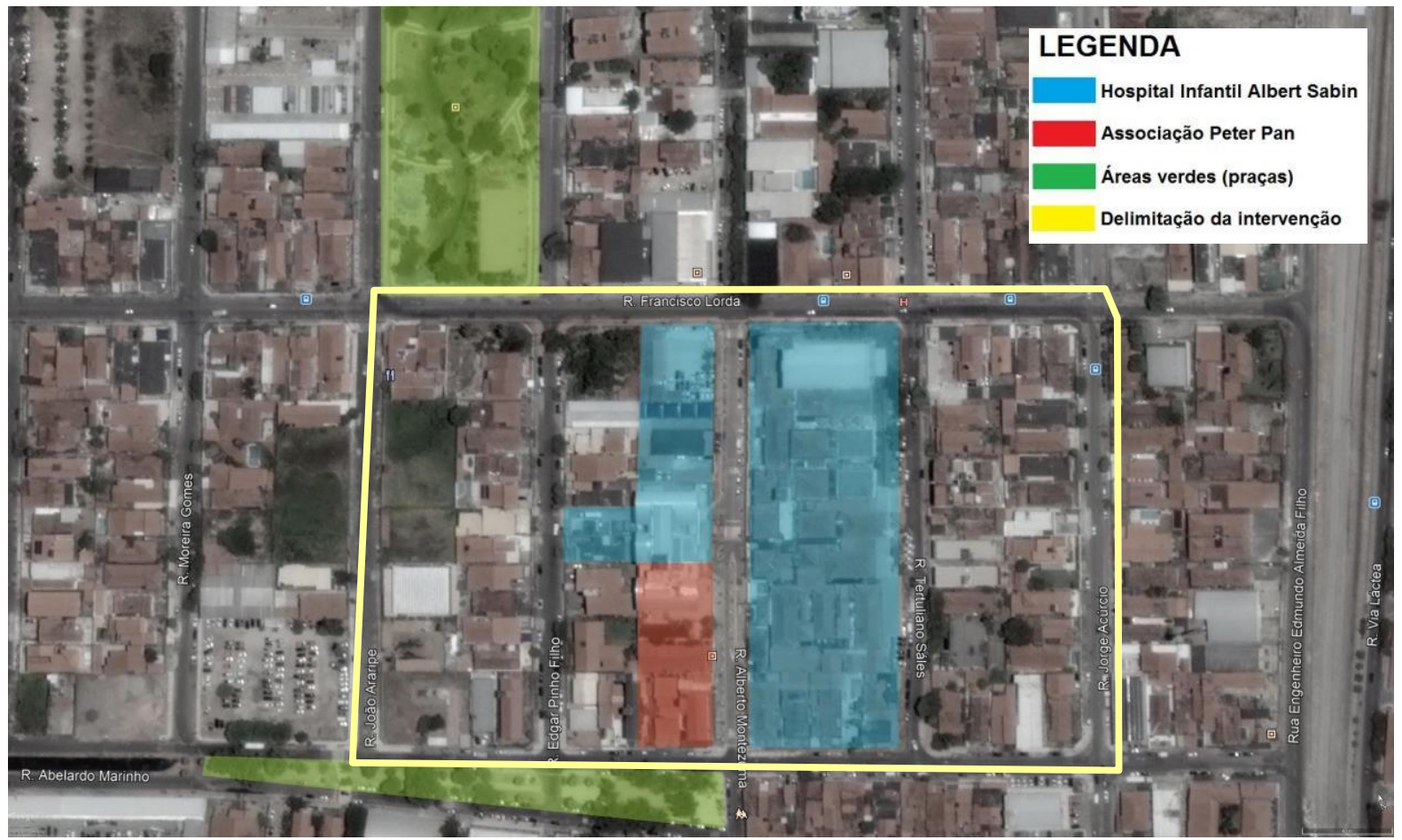

Fonte: Google Earth. Editado pelos autores, 2018

\subsection{Intervenções avaliadas}

Os pontos de intervenção do projeto em avaliação foram: engorda de algumas esquinas, rampas de acesso às calçadas, a construção de uma passagem elevada, a expansão das calçadas na Rua Tertuliano Sales (lado oposto ao hospital) e na Rua Francisco Lorda (no trecho do hospital Albert Sabin), a demarcação de vagas, e algumas sinalizações verticais e horizontais. Além de ter reduzido a velocidade da Rua Francisco Lorda para $40 \mathrm{~km} / \mathrm{h}$ e das ruas Abelardo Marinho, Tertuliano Sales e Jorge Acúrcio para $30 \mathrm{~km} / \mathrm{h}$.

Inicialmente, falando das engordas, estas foram realizadas em algumas esquinas da região. Já apontando as suas funções positivas, pode-se ressaltar como a maior, a diminuição da 


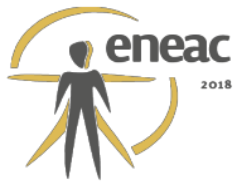

travessia do pedestre na via. Além disso, nestas mesmas engordas, foram executadas rampas de acesso às calçadas (outro ponto positivo).

Figura 2 - Semáforo da Rua Tertuliano Sales com Francisco Lorda antes da intervenção

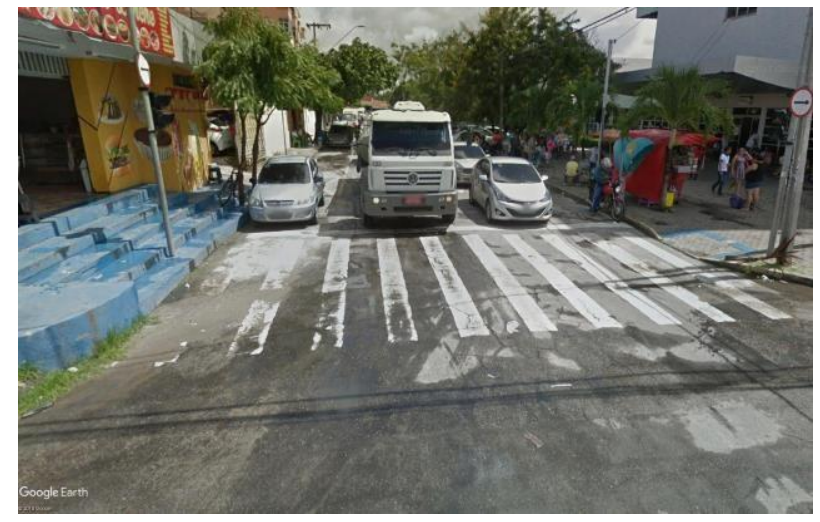

Fonte: Google Earth, março de 2017

\section{Figura 3 - Semáforo da Rua Tertuliano Sales com Francisco Lorda após a intervenção}

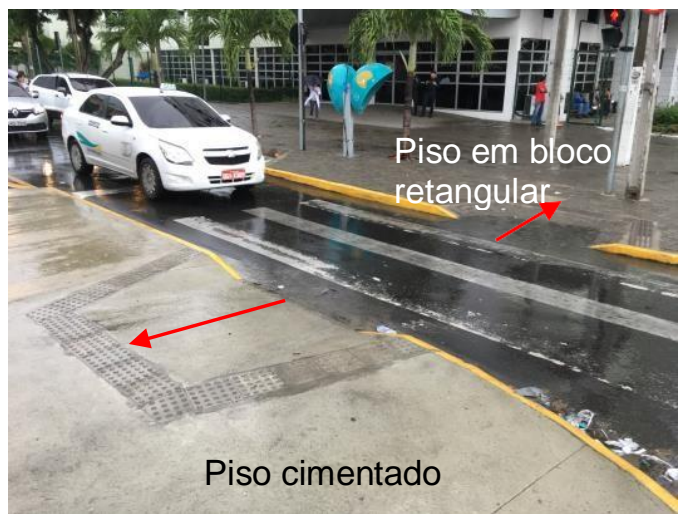

Fonte: Acervo dos autores, 2018

Estas duas intervenções foram realizadas com piso cimentado, excetuando pela esquina da calçada do hospital que utilizou o piso existente (bloco retangular de concreto cinza).

Figura 4 - Cruzamento da Rua Tertuliano Sales com Abelardo Marinho antes da intervenção

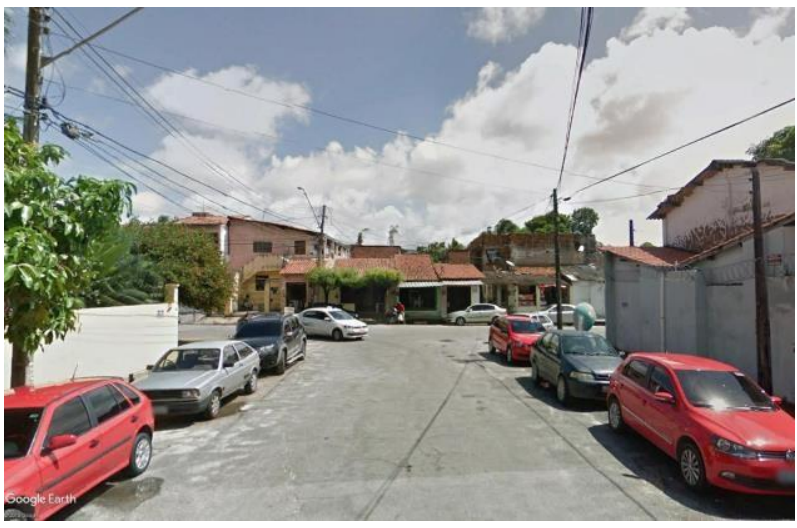

Fonte: Google Earth, março 2017
Figura 5 - Cruzamento da Tertuliano Sales com Abelardo Marinho após a intervenção

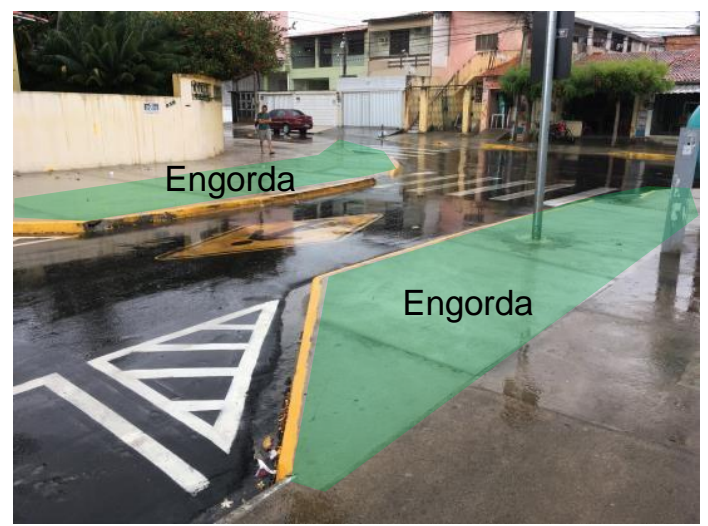

Fonte: Acervo dos autores, 2018

Outro ponto positivo a ser destacado por este tipo de intervenção é o não estacionamento de veículos nas esquinas. Prática que acontecia frequentemente antes da obra. Além disso, houve uma limitação no número de vagas para veículos.

Porém, alguns pontos negativos puderam ser vistos: algumas rampas estão com inclinação acima do limite permitido em norma (10\% para desnível de até $20 \mathrm{~cm}$, em casos excepcionais). A rampa apresentada nas figuras 6 e 7, por exemplo, está com 13,3\% de inclinação, pois, a calçada tem uma altura de $20 \mathrm{~cm}$ e a rampa tem $1,50 \mathrm{~m}$ de extensão. Além disso, ainda existe um desnível de $3 \mathrm{~cm}$ em seu início. Na avaliação foi verificado que tal rampa tem espaço suficiente para atender a norma de inclinação de até $8,33 \%$ para desníveis até $80 \mathrm{~cm}$ em casos comuns de construção de rampas. 


\section{Time}

Figura 6 - Rampa com 13,3\% de inclinação

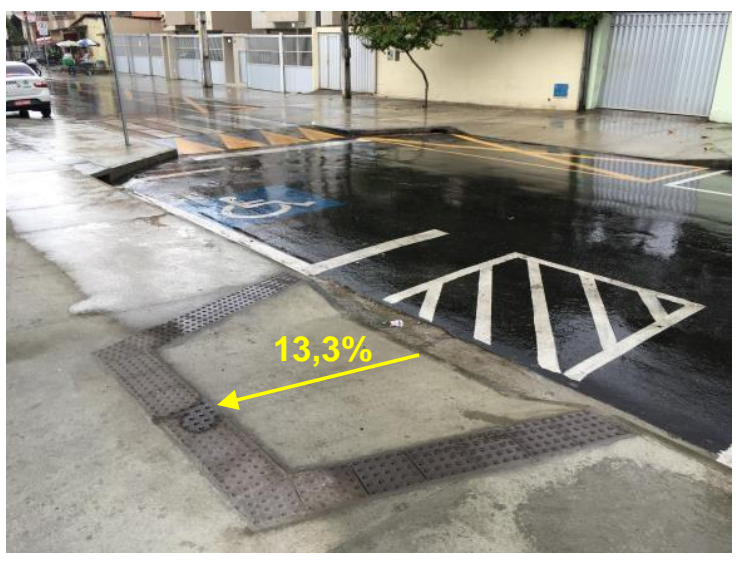

Fonte: Acervo dos autores, 2018
Figura 7 - Rampa com desnível

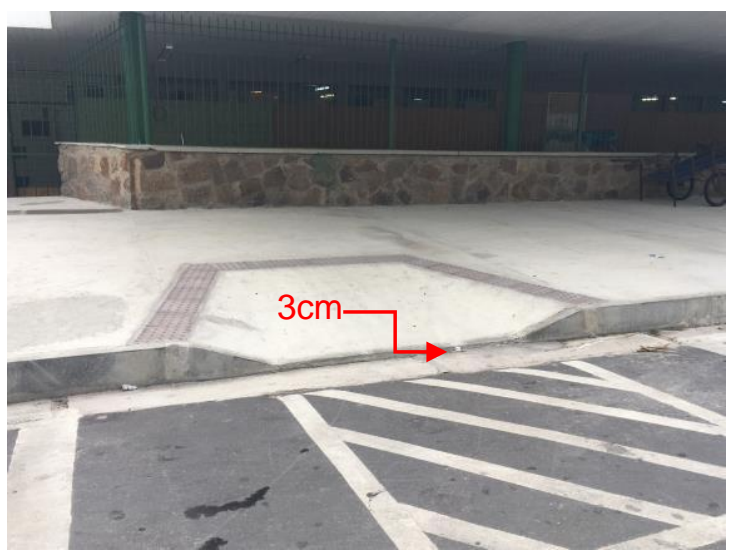

Fonte: Acervo dos autores, 2018

Outro ponto negativo a ser ressaltado é em decorrência da incompatibilidade de projetos complementares ou até mesmo a ausência de algum deles. Na maioria das rampas executadas, assim que a pessoa sobe, ela encontra um obstáculo (poste de iluminação ou de sinalização, outra rampa, muro de uma edificação, etc.). Esta problemática se dá pelo custo elevado que é, por exemplo, a subtração de postes e execução de instalações subterrâneas. Mas também podemos levar em conta o efeito bola de neve, em que a tentativa de solução acaba esbarrando com outro problema (ver figuras 8 e 9), ou até mesmo, a execução automática da obra sem uma análise de sua coerência.

\section{Figura 8 - Rampa construída encontrando rampa existente}

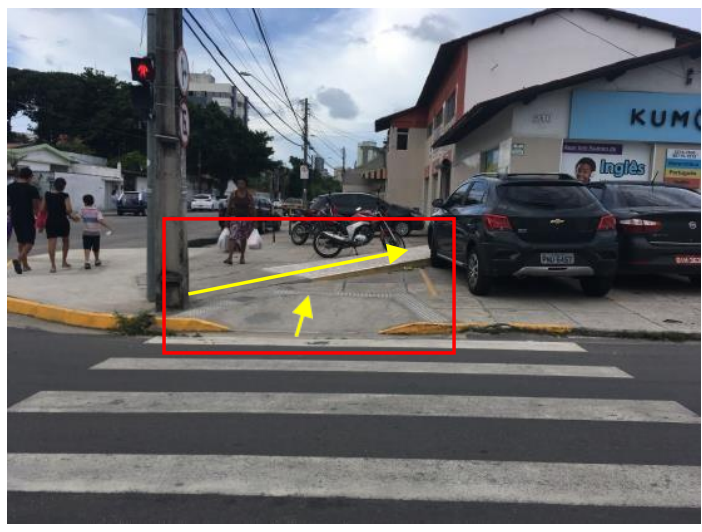

Fonte: Acervo dos autores, 2018
Figura 9 - Rampa construída encontrando muro de comércio

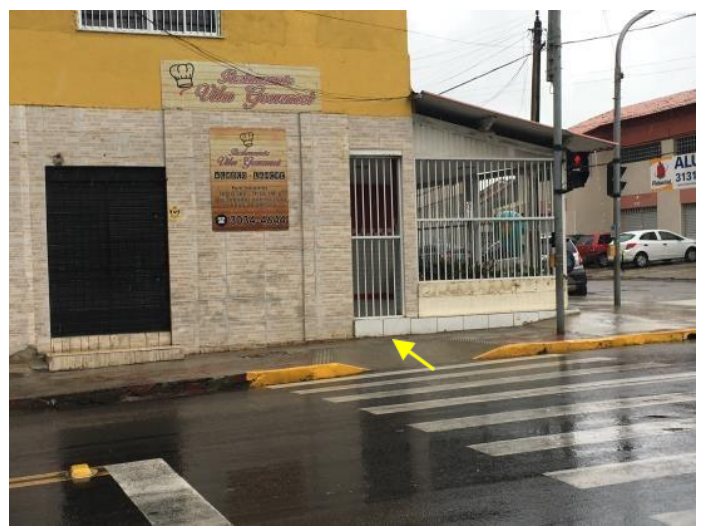

Fonte: Acervo dos autores, 2018

Além disso, no período de chuva, se não houver projeto de drenagem eficiente, as rampas viram pequenas piscinas com águas pluviais (ver figura 3).

Continuando sobre as intervenções, a outra medida realizada foi a construção de uma passagem (faixa) elevada com engordas laterais. Esta solução evita o rebaixamento do meio-fio para a construção de mais rampas e mantém o pedestre se locomovendo de maneira segura e mais confortável. Além disso, os veículos são obrigados a reduzir a velocidade para realizar a travessia, dando mais segurança aos pedestres. 


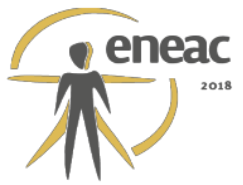

Um ponto positivo na execução da passagem elevada foi a construção das valas (sarjetas) cobertas de escoamento das águas, em ambas laterais. Isso evitará possíveis alagamentos.

\section{Figura 10 - Passagem elevada}

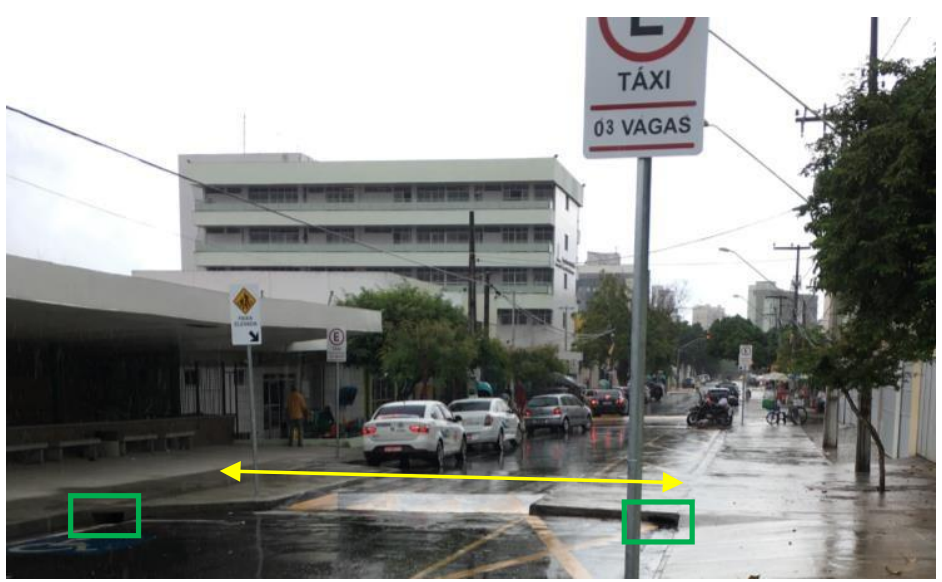

Fonte: Acervo dos autores, 2018

A próxima intervenção avaliada foi o enlarguecimento de trechos de calçadas, trazendo mais espaço para os pedestres se locomoverem com segurança, além de formar juntamente com as engordas, baias que organizam o estacionamento de veículos. Vale ressaltar que, com este aumento de área, foi possível instalar bancos de concreto em uma faixa linear próxima ao meio-fio (faixa de serviço), garantindo área de livre passeio com dimensão ideal expressado em norma, refletindo assim, em uma boa caminhabilidade.

De acordo com o professor Julio Pozueta (2009), um dos requisitos para definir itinerários caminháveis é o conforto, pois, este diz que os espaços devem ser amplos, bem pavimentados, com declividades moderadas, dotados de equipamentos públicos (bancos, telefones, etc.), entre outros.

Figura 11 - Calçada nova com bancos

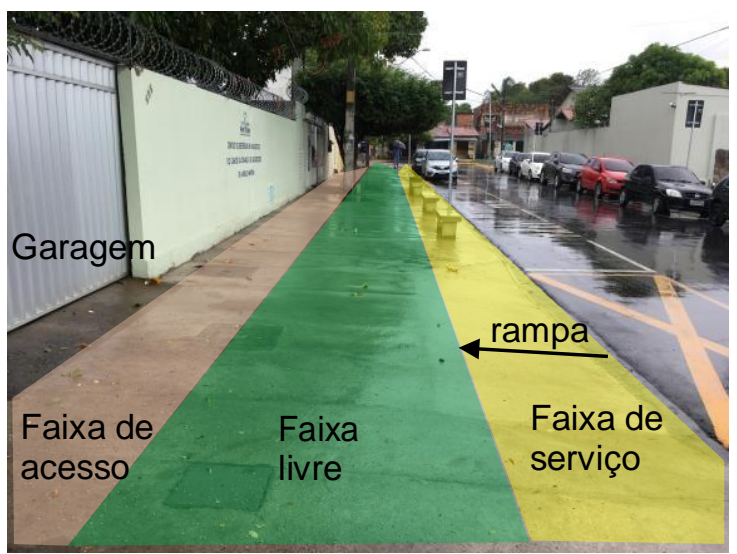

Fonte: Acervo dos autores, 2018
Figura 12 - Calçada com barreira física

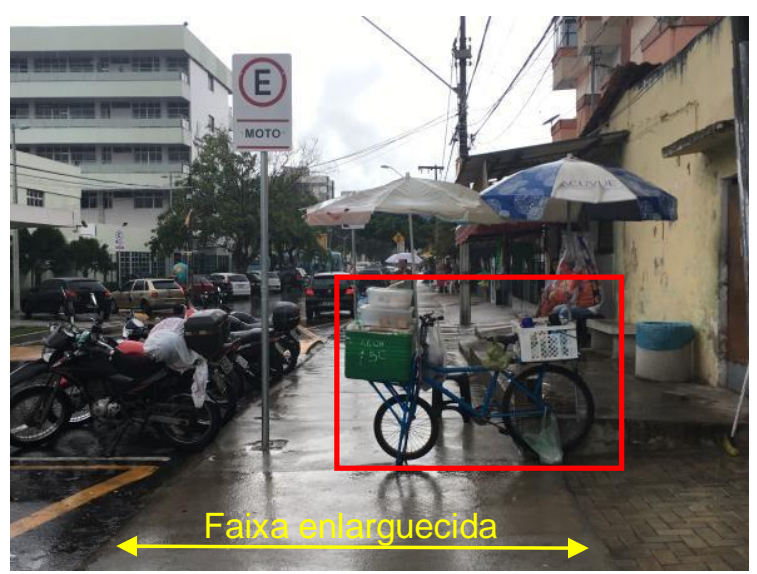

Fonte: Acervo dos autores, 2018

Porém, algo negativo deve-se pontuar: a falta de sensibilidade das próprias pessoas que ali frequentam. Isto demonstra que mudanças atitudinais devem ocorrer e que elas devem fazer parte de um projeto que a própria prefeitura municipal poderia realizar, 


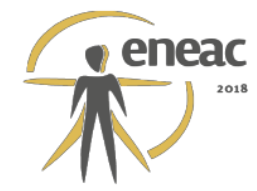

conscientizando os ambulantes e pequenos comerciários locais a não colocarem seus carrinhos, bicicletas, cadeiras, mesas e outras barreiras físicas na faixa livre de passeio ou sobre o piso tátil quando existir.

Citando o uso do piso tátil, percebeu-se que ele só foi utilizado no tipo alerta nas delimitações das rampas. Além disso, a cor utilizada não contrasta com o piso novo realizado. O uso resumido do piso tátil deixou a situação vulnerável para as pessoas se acidentarem em obstáculos como: postes, orelhões, mudanças de nível, entre outros. Observando a figura 13, o questionamento fica no ar: o que é mais problemático? A falta de piso de alerta ou os vários obstáculos aglomerados em uma mesma esquina?

\section{Figura 13 - Obstáculos sem piso de alerta ao redor}

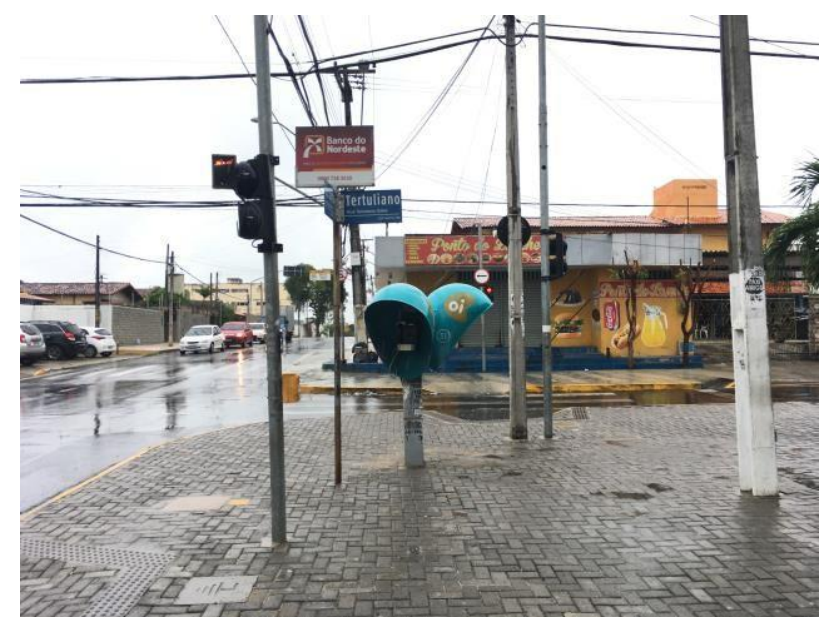

Fonte: Acervo dos autores, 2018

Também, levando em consideração a temática de piso, foram encontradas em uma mesma calçada (na entrada principal do hospital Albert Sabin) três tipos de revestimento: cimentado, pedra portuguesa e bloco retangulares de concreto. Estes dois últimos são revestimentos que dão uma maior possibilidade de acidentes devido aos sulcos formados entre as peças. Além disso, a mudança de piso acaba por confundir um deficiente visual que necessita reconhecer onde pisa através da sua bengala.

Figura 14 - Encontro tipos de pisos

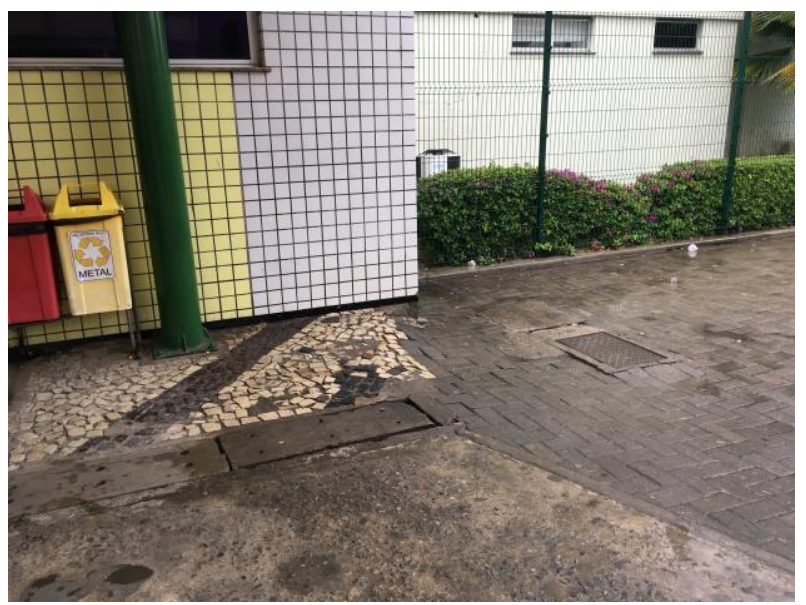

Fonte: Acervo dos autores, 2018 
Em suma, várias intervenções realizadas e algumas malsucedidas devido a não compreensão correta dos projetos ou a não instrução de quem vai executar. Problemas uns que foram amenizados, problemas outros que foram ressaltados. As dificuldades são diversas e a prova disto é vista nitidamente quando tudo está finalizado.

\section{CONSIDERAÇÕES FINAIS}

Este trabalho buscou avaliar a situação em que se encontra um trecho do bairro Vila União que fora recentemente requalificado pela Prefeitura Municipal de Fortaleza.

O que se tinham como focos iniciais das intervenções eram: a priorização e a promoção da segurança dos pedestres que ali circulam, já que na região está instalado um dos mais importantes hospitais de Fortaleza (Hospital Infantil Albert Sabin). Para isto ocorrer, foram introduzidos, nas vias envolvidas, itens específicos para facilitar a acessibilidade.

Outro detalhe importante é que a Rua da Esperança foi um marco introdutório de tais intervenções. Ela foi idealizada como um espaço aberto, de convivência para as pessoas do hospital, e planejada para ser um lugar de tráfico calmo e seguro para os pedestres.

Enfim, todas as intervenções foram pensadas priorizando o reordenamento dos passeios e das vias, a segurança dos pedestres, o transporte público e toda a sistemática urbana envolvida.

Porém, o que foi constatado é que o simples atendimento dos itens preestabelecidos pela legislação e a normatização brasileira não é capaz de dotar um espaço público de efetiva acessibilidade, principalmente para as pessoas com deficiência ou mobilidade reduzida. Toda uma ação bem estruturada coordenada pelo gestor, no caso a prefeitura municipal, poderia garantir a efetiva acessibilidade geral e irrestrita; mas, não é a simples eliminação de barreiras físicas que garante o direito de ir e vir a todos.

Assim, é um desafio para arquitetos e engenheiros dotar os espaços públicos de informações eficientes e soluções espaciais adequadas para as inúmeras pessoas que ali frequentam. O conhecimento deste assunto, que é a acessibilidade, é fundamental tanto para o profissional da construção civil como para o cidadão que está envolvido na promoção de uma cidade mais igualitária.

Pode-se perceber que esta falta de conhecimento ou até mesmo de sensibilidade das pessoas tornam a solução do projeto arquitetônico idealizado em algo não eficiente ou malsucedido. A construção sem conhecimento termina, por exemplo, na execução de rampas com inclinações indevidas e pisos inapropriados. Ou seja, a falta de um conhecimento mais amplo da importância da acessibilidade, por quem executa a obra, pode gerar um gasto desnecessário ou a reexecução das intervenções.

Ressalta-se que a problemática não recai apenas no construtor (executor das obras). Todos os agentes envolvidos devem participar de todos os processos das intervenções. A integração das diversas áreas e o trabalho em conjunto é fundamental para a eficiência do projeto como um todo. $\mathrm{Na}$ área em estudo, foram encontradas algumas incongruências entre a intervenção pensada e a atuação de certos órgãos responsáveis. Puderam-se ver postes e telefones públicos posicionados de tal maneira que debilitavam o uso de algumas rampas por exemplo. A efetiva drenagem também foi uma ausência percebida pelas poças que se formaram após alguns minutos de chuva. Além disso, destaca-se a questão de até onde é responsabilidade da iniciativa pública e a partir de quando a iniciativa privada tem que intervir.

Vale ressaltar, também, que reformas e adaptações são mais dispendiosas do que já se pensar em uma edificação ou uma cidade acessível desde o seu principio. É a partir deste 


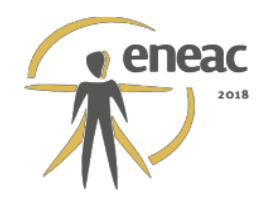

pensamento de combater o retrabalho e colocar a acessibilidade como condição tão importante como os demais itens projetuais, que o termo Desenho Universal vem sendo cada vez mais utilizado no mundo da arquitetura.

Diante de tudo o que foi exposto, observou-se que existe um longo caminho a ser trilhado no que diz respeito à compreensão total do que seria acessibilidade. Deve-se entender que só o estudo pode levar ao conhecimento dos múltiplos aspectos - físicos, sociais, culturais, históricos, entre outros. É imprescindível superar estes obstáculos de conhecimento e sensibilidade, e continuar buscando, todos juntos (pessoas com ou sem deficiência), as melhores soluções para as inúmeras barreiras ao direito de ir e vir.

\section{REFERÊNCIAS BIBLIOGRÁFICAS}

ASSOCIAÇÃO BRASILEIRA DE NORMAS TÉCNICAS. NBR 9050 Acessibilidade a edificações, mobiliários, espaços e equipamentos urbanos. 2015.

CHOAY, Françoise. O Urbanismo: utopias e realidades. Uma Antologia. São Paulo, 1979.

DUARTE, Cristiane Rose; COHEN, R. Research and Teaching of Accessibility and Universal Design on Brazil: Hindrances and Challenges in a Developing Country. In: Nasar, J.; EvansCowley,J. (Org.). Universal Design and Visitability: from Accessibility to Zoning. 1ed. Columbus: National Endowment for the arts, 2007.

FORTALEZA, Prefeitura Municipal. Decreto $n^{\circ}$ 13.142, de 29 de abril de 2013. Regulamenta a realização de parceria com a iniciativa provada e a sociedade civil organizada para a manutenção de espaços públicos no Município de Fortaleza. Diário Oficial do Município de Fortaleza. Fortaleza, 2013.

FORTALEZA, Prefeitura Municipal. Catálogo de Serviços - Mobilidade. Disponível em: https://catalogodeservicos.fortaleza.ce.gov.br/categoria/mobilidade . Acessado em janeiro de 2018.

HANDICAP INTERTIONAL. Documento de Estratégia para a Redução da Pobreza (PRS).

Disponível em: http://www.making-prsp-inclusive.org . Acessado em janeiro de 2018.

POZUETA, Echevarri Julio. La ciudad paseable. Madrid, 2009.

UNIDAS, Organismos das Nações. Convenção dos Direitos das Pessoas com Deficiência. Disponível em: https://www.un.org/development/desa/disabilities/. Acessado em janeiro 2018.

ZURBA, Nadia Khaled. Como salvar vidas de pessoas com deficiências em emergências? A invenção e o desenvolvimento de novos pisos táteis fotoluminescentes. Fortaleza, 2016. 